\title{
Emergency Laparotomy Outcomes: Higher First-Year Mortality in the Elderly
}

\section{Dear Editor,}

Emergency laparotomy (EL) is a common procedure in the treatment of a myriad of potentially life-threatening abdominal conditions. Unlike elective surgery, EL is associated with high morbidity and mortality. ${ }^{1-3}$ Compared to their younger counterparts, elderly patients are at higher risk of postoperative complications and mortality that are attributed to multiple comorbidities and reduced physiological reserves. ${ }^{3-5}$ Additionally, patients who require EL tend to be critically ill with limited time for preoperative optimisation. Studies on EL have revealed substantial variations in processes and lack of coordination of EL care. ${ }^{6-8}$

In the United Kingdom (UK), the National Emergency Laparotomy Audit (NELA) has shown a reduction in 30-day mortality from $11.8 \%$ to $9.5 \%$ since $2013 .{ }^{6}$ In its third report, NELA described 9 key standards that can improve efficiency in the management of EL patients. To date, there is no standard practice in EL management in our institution and postoperative EL outcomes in Singapore are not known. In this study, we described EL outcomes in an acute hospital in Singapore, determined factors associated with 30-day mortality and explored perioperative outcomes in elderly patients.

\section{Materials and Methods}

We performed a retrospective cohort study of EL outcomes from January 2017 to December 2017 in a local institution. Patients $\geq 16$ years old who underwent EL were included. Similar to NELA, the exclusion criteria included laparotomies for trauma, vascular or gynaecology emergencies. Relook laparotomies were also excluded.

Data collected included patient demographics, diagnoses and preoperative risk assessment such as Portsmouth Physiological and Operative Severity Score for the enumeration of Mortality and morbidity (P-POSSUM) scores and efficiency outcomes. Patients were classified as either young $(<65$ years old) or elderly ( $\geq 65$ years old). The American Society of Anaesthesiologists (ASA) Physical Status Classification System was used to assess the physical state of patients prior to EL. The priority (P) accorded to each EL was also recorded. In our institution, $\mathrm{P} 1$ refers to procedures that are performed within 1 hour, P2 for procedures undertaken within 4 hours and P3 denote those that take place within 24 hours. Postoperative complications were graded according to the Clavien-Dindo classification system. Data on length of stay (LOS), 30-day mortality and annual mean cost to hospital (total bill without subsidy awarded by the state) were evaluated.

Data analysis was performed using IBM SPSS Statistics for Windows, Version 22.0 (IBM Corp., Armonk, NY, USA). For categorical variables, counts and percentages were reported. Parametric data were reported in mean and standard deviation (SD). Differences were assessed using Student's t-test for continuous data; for categorical data, chi-square or Fisher's Exact test was used. A value of $P<0.05$ was considered statistically significant.

\section{Results}

A total of 152 patients were included in the study. Most of them were Chinese (74.3\%). There were 96 (63.2\%) men and $80(52.6 \%)$ patients were $>65$ years old. A total of $73(48.0 \%), 44(28.9 \%)$ and $20(13.2 \%)$ patients were graded ASA II, III and IV, respectively. Forty-nine (32.2\%) patients had P-POSSUM mortality risk $\geq 10 \%$. As shown in Table 1, the most common indications for EL were perforated peptic ulcer disease (22.4\%), obstructed or perforated colonic tumours $(20.4 \%)$ and adhesion-related intestinal obstruction (15.1\%).

Preoperative computed tomography (CT) was performed on most patients (86.2\%). Mean duration from booking of operative case to EL ranged from 92 (SD 26) minutes for P1 cases to 171 (SD 76) minutes for $\mathrm{P} 2$ cases and 510 (SD 319) minutes for P3 cases. The procedure was supervised by a senior anaesthetist and senior surgeon in $47(30.9 \%)$ and $140(92.1 \%)$ cases, respectively. A total of 71 (46.7\%) EL were performed during the day (Table 2).

Postoperatively, 39 (25.7\%) patients were monitored in Intensive Care Unit (ICU), 18 (11.8\%) in High Dependency Unit (HDU) and the remainder in General Ward. In patients with P-POSSUM mortality risk 
Table 1. Demographic and Preoperative Characteristics of Patients

\begin{tabular}{|c|c|c|c|c|}
\hline Variable & $\begin{array}{l}\text { Aggregate } \\
(n=152)\end{array}$ & $\begin{array}{c}<65 \text { Years Old } \\
(n=72)\end{array}$ & $\begin{array}{c}\geq 65 \text { Years Old } \\
(n=80)\end{array}$ & $P$ Value \\
\hline Mean age in years (SD) & $63(16)$ & $49(11)$ & $75(7)$ & $<0.01$ \\
\hline Gender $(\%)$ & & & & 0.49 \\
\hline Male & $96(63.2)$ & $48(66.7)$ & $48(60.0)$ & \\
\hline \multicolumn{5}{|l|}{ Ethnicity (\%) } \\
\hline Chinese & $113(74.3)$ & $45(62.5)$ & $68(85.0)$ & $<0.01$ \\
\hline Malay & $24(15.8)$ & $12(16.7)$ & $12(15.0)$ & 0.95 \\
\hline Indian & $10(6.6)$ & $10(13.9)$ & $0(0)$ & $<0.01$ \\
\hline \multicolumn{5}{|l|}{ ASA Physical Status score (\%) } \\
\hline 1 & $15(9.9)$ & $14(19.5)$ & $1(1.3)$ & $<0.01$ \\
\hline 2 & $73(48.0)$ & $38(52.7)$ & $35(43.7)$ & 0.34 \\
\hline 3 & $44(28.9)$ & $14(19.5)$ & $30(37.5)$ & 0.02 \\
\hline 4 & $20(13.2)$ & $6(8.3)$ & $14(17.5)$ & 0.15 \\
\hline \multicolumn{5}{|l|}{ Indication for surgery $(\%)$} \\
\hline Perforated gastric/duodenal ulcer & $34(22.4)$ & $15(20.8)$ & $19(23.8)$ & 0.81 \\
\hline Colorectal cancer (obstructed/perforated) & $31(20.4)$ & $17(23.6)$ & $14(17.5)$ & 0.46 \\
\hline Intestinal obstruction secondary to adhesions & $23(15.1)$ & $10(13.9)$ & $13(16.2)$ & 0.86 \\
\hline Perforation of intestine & $19(12.5)$ & $7(9.7)$ & $12(15.0)$ & 0.46 \\
\hline Anastomotic leak & $12(7.9)$ & $7(9.7)$ & $5(6.2)$ & 0.62 \\
\hline Bleeding & $4(2.6)$ & $4(5.6)$ & $0(0)$ & 0.048 \\
\hline Intestinal obstruction (bezoar/foreign bodies) & $5(3.3)$ & $1(1.4)$ & $4(5.0)$ & 0.37 \\
\hline Non-malignant intestinal obstruction & $5(3.3)$ & $3(4.2)$ & $2(2.5)$ & 0.67 \\
\hline Gallstone ileus & $3(2.0)$ & $0(0)$ & $3(3.8)$ & 0.25 \\
\hline \multicolumn{5}{|l|}{ Preoperative P-POSSUM } \\
\hline Mean morbidity score (SD) & $65.0(23.6)$ & $58.7(24.0)$ & $70.7(21.8)$ & $<0.01$ \\
\hline Mean mortality score (SD) & $11.4(14.2)$ & $8.9(13.9)$ & $13.7(14.1)$ & 0.04 \\
\hline Low $(<5 \%), \%$ & $74(48.7)$ & $43(59.7)$ & $31(38.7)$ & 0.02 \\
\hline Medium $(5-10 \%), \%$ & $29(19.1)$ & $14(19.5)$ & $15(18.8)$ & 0.91 \\
\hline High $(>10 \%), \%$ & $49(32.2)$ & $15(20.8)$ & $34(42.5)$ & $<0.01$ \\
\hline Documentation of risk assessment and counselling (\%) & $0(0)$ & $0(0)$ & $0(0)$ & NA \\
\hline Preoperative CT (\%) & $131(86.2)$ & $65(90.3)$ & $66(82.5)$ & 0.25 \\
\hline
\end{tabular}

ASA: American Society of Anaesthesiologists; CT: Computed tomography; NA: Not applicable; P-POSSUM: Portsmouth Physiological and Operative Severity Score for the enumeration of Mortality and morbidity; SD: Standard deviation 
$\geq 10 \%, 38(77.6 \%)$ of them were managed by the Critical Care team. For postoperative complications, $29(19.1 \%)$ patients were graded III to V on ClavienDindo classification system. Mean LOS was 15.4 (SD 17.0) days. Mortality rates at 30 days and 1 year were $5.3 \%$ and $9.2 \%$, respectively. Mean annual cost to the institution was S\$14,152 (SD S\$15,860) for each patient (Table 3 ).

Factors associated with increased mortality included P-POSSUM mortality risk $\geq 10 \%$ (odds ratio [OR] $4.217, P<0.05$ ), ASA score of 4 (OR 9.265, $P<0.01$ ) and postoperative complications (OR 11.0, $P<0.01$ ). Subgroup analysis of $80(52.6 \%)$ elderly patients revealed that they had higher ASA III scores than young patients $(37.5 \%$ vs $19.5 \%, P=0.02)$. P-POSSUM morbidity and mortality were also higher in elderly patients $(P<0.01$ and $P=0.04$, respectively). Finally, more elderly $(35.0 \%)$ patients were monitored in ICU than young $(15.3 \%)$ patients $(P<0.01)$.

Elderly $(20.0 \%)$ patients had more severe postoperative complications-Clavien-Dindo IV-than younger $(1.4 \%)$ patients $(P<0.01)$. More elderly $(7.5 \%)$ patients also had another unplanned procedure performed on them than on their younger $(2.8 \%)$ counterparts $(P=$ 0.28 ). As shown in Table 3 , mean LOS in elderly patients was 19.0 (SD 21.6) days against 11.3 (SD 7.8) days in younger patients $(P<0.01)$. In elderly patients, the 30 day mortality rate was $8.8 \%$ but only $1.4 \%$ in younger patients. More of them (35.1\%) were discharged to stepdown care against $4.2 \%$ of younger patients who did so $(P<0.01)$. However, readmissions at 30 days were similar in both groups: $6.2 \%$ in the elderly group and $6.9 \%$ in the younger group $(P=0.86)$. At 1 year, the mortality rate in the elderly and younger group was $15.0 \%$ and $2.8 \%$, respectively $(P=0.01)$.

\section{Discussion}

Much effort has been made to improve outcomes following EL including NELA in the UK and ANZ Emergency Laparotomy Audit and Quality Improvement project in Australia and New Zealand. ${ }^{9}$ In the UK, NELA had demonstrated a reduction in mortality rate from $11.8 \%$ in 2013 to $9.5 \%$ in 2018 . In 2017 , cost savings of up to 24 million pounds and 108,000 bed-days in acute public hospitals were achieved. In contrast, data on outcomes following EL in Asia is lacking. This is the first emergency laparotomy audit in an acute public hospital in Singapore that described care processes and patient outcomes following EL.

In our study, the finding of a 30-day mortality rate of $5.3 \%$ was lower than that found by NELA which was $9.5 \%$. P-POSSUM and ASA scores were also accurate predictors of mortality and morbidity following emergency surgery and laparotomies, respectively. ${ }^{10,11}$ These findings highlight the importance of a standardised preoperative risk assessment in the identification of high-risk patients who may benefit from reviews by senior anaesthetists and senior surgeons to reduce postoperative complications and mortality.

Table 2. Efficiency Outcomes

\begin{tabular}{|c|c|c|c|c|}
\hline Outcome & $\begin{array}{c}\text { Aggregate } \\
(\mathrm{n}=152)\end{array}$ & $\begin{array}{c}<65 \text { Years Old } \\
\quad(n=72)\end{array}$ & $\begin{array}{c}\geq 65 \text { Years Old } \\
(n=80)\end{array}$ & $P$ Value \\
\hline \multicolumn{5}{|l|}{ Mean duration to OT in minutes (SD) } \\
\hline P1 (within 60 minutes) & $92(26)$ & $95(30)$ & $90(22)$ & 0.68 \\
\hline P2 (within 240 minutes) & $171(76)$ & $151(58)$ & $188(85)$ & $<0.01$ \\
\hline P3 (within 720 minutes) & $510(319)$ & $395(295)$ & $652(326)$ & 0.25 \\
\hline P-POSSUM $\geq 10 \%$ & $27.5(15.1)$ & $30.1(18.9)$ & $26.5(13.3)$ & 0.46 \\
\hline Supervision by senior surgeon in OT (\%) & $140(92.1)$ & $68(94.4)$ & $72(90.0)$ & 0.38 \\
\hline P-POSSUM $\geq 10 \%$ & $46(93.9)$ & $15(100)$ & $31(91.2)$ & 0.54 \\
\hline Supervision by senior anaesthetist in OT (\%) & $47(30.9)$ & $24(33.3)$ & $23(28.8)$ & 0.66 \\
\hline P-POSSUM $\geq 10 \%$ & $12(24.5)$ & $4(26.7)$ & $8(23.5)$ & 1.0 \\
\hline Time of surgery $(\%)$ & & & & 0.71 \\
\hline $0730-1700$ hours & $71(46.7)$ & $32(44.4)$ & $39(48.8)$ & \\
\hline $1700-0730$ hours & $81(53.3)$ & $40(55.6)$ & $41(51.2)$ & \\
\hline
\end{tabular}

OT: Operating theatre; P-POSSUM: Portsmouth Physiological and Operative Severity Score for the enumeration of Mortality and morbidity; SD: Standard deviation 
Our study met 5 of 9 key standards on efficiency and organisational outcomes that were described in the third patient report by NELA. Most of our patients underwent preoperative $\mathrm{CT}$ that was performed by a radiologist who was of the registrar grade. Arrival at the operating theatre took place within the prescribed time interval and mean wait time for P2 and P3 cases were only about 1 hour.

Although P-POSSUM was performed retrospectively in our study, senior surgeons reviewed the results and supervised most procedures when the risk was $\geq 10 \%$. In our institution, there is no consensus to direct all postoperative admissions to HDU/ICU when P-POSSUM mortality risk was $\geq 10 \%$. The decision on HDU/ICU admission is based on a global assessment of the patient by the senior surgeon who uses P-POSSUM as a guide, but not as the sole determinant for doing so.

Postoperatively, elderly patients were not routinely reviewed by a dedicated team headed by a geriatrician. By 2030 , the population of Singaporeans $>65$ years old

Table 3. Clinical Outcomes

\begin{tabular}{|c|c|c|c|c|}
\hline Outcome & $\begin{array}{l}\text { Aggregate } \\
(n=152)\end{array}$ & $\begin{array}{c}<65 \text { Years Old } \\
(n=72)\end{array}$ & $\begin{array}{c}\geq 65 \text { Years Old } \\
(n=80)\end{array}$ & $P$ Value \\
\hline \multicolumn{5}{|l|}{ Postoperative admission (\%) } \\
\hline GW & $95(62.5)$ & $51(70.8)$ & $44(55.0)$ & 0.06 \\
\hline HDU & $18(11.8)$ & $10(13.9)$ & $8(10.0)$ & 0.62 \\
\hline ICU/HDU (P-POSSUM $\geq 10 \%)$ & $38 / 49(77.6)$ & $11 / 15(73.3)$ & $27 / 34(79.4)$ & 0.72 \\
\hline \multicolumn{5}{|l|}{ CD complications score $(\%)$} \\
\hline III & $7(4.6)$ & $4(5.6)$ & $3(3.8)$ & 0.71 \\
\hline IV & $17(11.2)$ & $1(1.4)$ & $16(20.0)$ & $<0.01$ \\
\hline III - V & $29(19.1)$ & $6(8.3)$ & $23(28.8)$ & $<0.01$ \\
\hline \multicolumn{5}{|l|}{ Hospital discharge (\%) } \\
\hline Against medical advice & $3(2.1)$ & $2(2.8)$ & $1(1.3)$ & 0.60 \\
\hline Normal discharge & $6(4.1)$ & $5(7.1)$ & $1(1.4)$ & 0.10 \\
\hline Outpatient follow-up & $106(73.1)$ & $61(85.9)$ & $45(60.8)$ & $<0.01$ \\
\hline Community hospital & $29(20.0)$ & $3(4.2)$ & $26(35.1)$ & $<0.01$ \\
\hline Nursing home & $1(0.7)$ & $0(0)$ & $1(1.4)$ & 1.0 \\
\hline \multicolumn{5}{|l|}{ Mean length of stay (SD) } \\
\hline $\mathrm{ICU}$ & $6.5(6.2)$ & $6.1(6.7)$ & $6.7(6.2)$ & 0.78 \\
\hline Overall & $15.4(17.0)$ & $11.3(7.8)$ & $19.0(21.6)$ & $<0.01$ \\
\hline Unplanned return to OT $(\%)$ & $8(5.3)$ & $2(2.8)$ & $6(7.5)$ & 0.28 \\
\hline Unplanned percutaneous abdominal drainage (\%) & $18(11.8)$ & $6(8.3)$ & $12(15.0)$ & 0.31 \\
\hline Unanticipated admission/return to ICU/HDU (\%) & $4(2.6)$ & $0(0)$ & $4(5.0)$ & 0.12 \\
\hline 30-day readmission $(\%)$ & $10(6.6)$ & $5(6.9)$ & $5(6.2)$ & 0.86 \\
\hline 30-day mortality (\%) & $8(5.3)$ & $1(1.4)$ & $7(8.8)$ & 0.07 \\
\hline 1-year mortality (\%) & $14(9.2)$ & $2(2.8)$ & $12(15.0)$ & 0.01 \\
\hline Mean hospital cost in SGD (SD) & $14,152(15,860)$ & $12,157(12,222)$ & $15,947(18,430)$ & 0.13 \\
\hline
\end{tabular}

CD: Clavien-Dindo; GW: General ward; HDU: High dependency unit; ICU: Intensive care unit; OT: Operating theatre; P-POSSUM: Portsmouth Physiological and Operative Severity Score for the enumeration of Mortality and morbidity; SD: Standard deviation; SGD: Singapore dollars 
is expected to reach $25 \% .^{12}$ The elderly represents a vulnerable group of patients with lower physiological reserves and higher risk of morbidity and mortality than younger patients; at 1 year, all-cause mortality from EL was higher in them $(15.0 \%)$ than in the latter $(2.8 \%, P=0.01)$. Using the key standards laid out by NELA as benchmarks in our study, our findings have highlighted opportunities for improvement.

A limitation of our study includes the inherent biases found in a retrospective study. For example, the presence of senior anaesthetists and senior surgeons were determined based solely on operative records. Consequently, the actual duration and extent of their involvement may be variable. Also, parameters such as intraoperative findings, degree of contamination and actual procedure were not examined since they may potentially enhance our understanding of postoperative outcomes in patients. Future studies could include standardised perioperative management of EL and comparison of multicentre data.

\section{Conclusion}

This is the first EL audit from our institution that reported a 30-day mortality of $5.3 \%$. Postoperative complications and mortality at 1 year were significantly higher in elderly patients. More studies and collaborative initiatives from Singapore are needed to evaluate the efficacy of outcome-driven, multidisciplinary perioperative care.

\section{REFERENCES}

1. National Emergency Laparotomy Audit. Fourth Patient Audit Report. Available at: https://www.nela.org.uk/Fourth-Patient-Audit-Report. Accessed on 25 October 2019.

2. Densham I. The emergency laparotomy - principles and perioperative management. Update in Anaesthesia 2016;31:2-8.

3. Aggarwal G, Peden CJ, Quiney NF. Improving outcomes in emergency general surgery patients: what evidence is out there? Anesth Analg 2017;125:1403-5.

4. Aggarwal G, Peden CJ, Mohammed MA, Pullyblank A, Williams B, Stephens T, et al. Evaluation of the collaborative use of an evidence-based care bundle in emergency laparotomy. JAMA Surg 2019;154:e190145.
5. Barrow E, Anderson ID, Varley S, Pichel AC, Peden CJ, Saunders DI, et al. Current UK practice in emergency laparotomy. Ann R Coll Surg Eng1 2013;95:599-603.

6. Royal College of Anaesthetists. National Emergency Laparotomy Audit (NELA). Available at: https://www.rcoa.ac.uk/research/ research-projects/national-emergency-laparotomy-audit-nela. Accessed on 6 April 2019.

7. Broughton KJ, Aldridge O, Pradhan S, Aitken RJ. The Perth Emergency Laparotomy Audit. ANZ J Surg 2017;87:893-7.

8. Saunders DI, Murray D, Pichel AC, Varley S, Peden CJ, UK Emergency Laparotomy Network. Variations in mortality after emergency laparotomy: the first report of the UK Emergency Laparotomy Network. Br J Anaesth 2012;109:368-75.

9. Royal Australasian College of Surgeons. ANZ Emergency Laparotomy Audit—Quality Improvement. Available at: https://www. surgeons.org/for-health-professionals/audits-and-surgical-research/ morbidity-audits/anzela-qi/. Accessed on 6 April 2019.

10. Thirunavukkarasu S, Subramanian AM. Efficacy of the P-POSSUM scoring system in prediction of post-operative mortality and morbidity in patients undergoing emergency laparotomy in a tertiary institute. Int Surg J 2018;5:2523-7.

11. Hopkins TJ, Raghunathan K, Barbeito A, Cooter M, Stafford-Smith M, Schroeder R, et al. Associations between ASA Physical Status and postoperative mortality at $48 \mathrm{~h}$ : a contemporary dataset analysis compared to a historical cohort. Perioper Med (Lond) 2016;5:29.

12. National Population and Talent Division, Prime Minister's Office, Singapore. Older Singaporeans to double by 2030 . Available at: https://www.population.sg/articles/older-singaporeans-to-doubleby-2030. Accessed on 6 April 2019.

Serene SN Goh, ${ }^{1}$ MBBS, MRCS (Edin),

Marc WJ Ong, ${ }^{1}$ MMed (Surgery), MRCS (Edin), FRCS (Edin), Woan Wui Lim, ${ }^{1}$ BSc (Nursing), MN (Trauma), Adv Dip (CCNC), Hilda $\mathrm{H} \mathrm{Hu},{ }^{2}{ }_{M B B S}$, Yvonne CL Wong, ${ }^{2}{ }_{M B B S}$, FANZCA, Kanak Naidu, ${ }^{3} M B B S, M D$, Jerry TT Goo, ${ }^{1}$ MMed (Gen Surg), MRCS (Edin), FRCS (Edin)

${ }^{1}$ Department of General Surgery, Khoo Teck Puat Hospital, Singapore ${ }^{2}$ Department of Anaesthesia, Khoo Teck Puat Hospital, Singapore ${ }^{3}$ Acute and Emergency Care, Khoo Teck Puat Hospital, Singapore

Address for Correspondence: Dr Serene Goh Si Ning, Department of General Surgery, Khoo Teck Puat Hospital, 90 Yishun Central, Singapore 768828.

Email: serene.goh@mohh.com.sg 